(Journal of Civil Engineering, Building and Transportation)

\title{
Perancangan Perletakan Elastomer berdasarkan Pedoman Perancangan Bantalan Elastomer untuk Perletakan Jembatan Tahun 2015
}

\section{Design of Elastomeric Bearings based on Design Guidelines for Elastomeric Bearings for Bridge laying in 2015}

\author{
Ahmad Sumantri \\ Program Studi Teknik Perancangan Jalan dan Jembatan, Jurusan Teknik Sipil \\ Politeknik Negeri Medan, Indonesia
}

*Corresponding Email: sumantri.ahmad@Gmail.com

\begin{abstract}
Abstrak
Sistim perletakan merupakan salah satu bagian terpenting dalam kostruksi jembatan. Jenis perletakan yang sering dipakai pada konstruksi jembatan adalah perletakan elastomer. Kesalahan dalam perhitungan perencanaan perletakan menimbulkan resiko keruntuhan pada kostruksi. Perancangan perletakan elastomer bertujuan untuk memahami perhitungan perancangan perletakan elastomer berdasarkan Pedoman Perancangan Bantalan Elastomer untuk Perletakan Jembatan Tahun 2015 dan mengetahui spesifikasi perletakan elastomer pada SNI 3967:2013. Perancangan perletakan elastomer disimulasikan pada Sungai Sei Tanjung pada proyek pembangunan Jalan Tol Trans Sumatera bagian pekerjaan Jalan Tol Ruas Indrapura - Kisaran. Perletakan yang tinjau adalah perletakan bantalan elastomer (elastomer bearing pads) tipe berlapis dengan dimensi: panjang elastomer (L) $=65 \mathrm{~cm}$, lebar $(\mathrm{W})=60 \mathrm{~cm}$, tebal $(\mathrm{H})=13,6 \mathrm{~cm}$, tebal lapisan penutup/cover $\left(\mathrm{hr}_{\text {cover }}\right)=1,15 \mathrm{~cm}$, tebal lapisan dalam/internal $\left(\mathrm{hr}_{\text {internal }}\right)=1,65 \mathrm{~cm}$, jumlah lapisan baja $\left(\mathrm{N}_{\text {layer }}\right)=7$ lapis, dan tebal baja pelat, $\mathrm{h}_{\mathrm{st}}=0,2$ $\mathrm{cm}$. Hasil perhitungan kontrol pada pembahasan menunjukan perletakan elastomer yang dipakai memenuhi persyaratan: tebal lapisan, tegangan tekan, rotasi, defleksi tekan, deformasi geser dan stabilitas.
\end{abstract}

Kata Kunci: Elastomer, Perletakan, Jembatan

\begin{abstract}
The bearing system is an important part of bridge construction. The type of placement that is often used in bridge construction is elastomeric placement. Errors in the calculation of the laying plan pose a risk of collapse in the construction. The design of elastomeric bearings aims to understand the calculation of the design of elastomeric bearings based on the Design Guidelines for Elastomeric Bearings for Bridge Laying in 2015 and to know the specifications for elastomeric placement in SNI 3967:2013. The design of the elastomeric placement is simulated on the Sei Tanjung River in the Trans Sumatra toll road construction project for the Indrapura - Kisaran toll road section. The placement under consideration is the placement of layered type elastomeric bearings with dimensions: elastomeric length $(\mathrm{L})=65 \mathrm{~cm}$, width $(W)=60 \mathrm{~cm}$, thickness $(H)=13,6 \mathrm{~cm}$, cover thickness $\left(\mathrm{hr}_{\text {cover }}\right)=1,15 \mathrm{~cm}$, internal layer thickness $(\mathrm{hr}$ internal $)=1,65 \mathrm{~cm}$, number of steel layers $\left(N_{\text {layer }}\right)=7$ layers, and steel plate thickness, $h_{s t}=0,2 \mathrm{~cm}$. The results of the control calculations in the discussion show that the elastomeric placement used meets the requirements: layer thickness, compressive stress, rotation, compressive deflection, shear deformation and stability.
\end{abstract}

Keywords: Elastomer, Bearing Pads, Bridge

How to Cite: Sumantri, A. (2021). Perancangan Perletakan Elastomer berdasarkan Pedoman Perancangan Bantalan Elastomer untuk Perletakan Jembatan Tahun 2015. JCEBT (Journal of Civil Engineering, Building and Transportation). 5 (2): 92 - 98 


\section{PENDAHULUAN}

Jembatan yang menjadi objek penelitian adalah jembatan Sungai (Sei) Tanjung pada proyek pembangunan jalan tol Indrapura-Kisaran Segmen 5. Jembatan tersebut merupakan jembatan Sungai (Sei) Tanjung yang berfungsi menghubungkan ruas jalan tol yang terputus akibat ada aliran sungai dibawahnya. Jenis jembatan yang dibangun adalah jembatan prategang yang panjang total 115 meter dan terdiri dari tiga segman jembatan yang masingmasing memiliki Panjang bentang 25 meter, 45,8 meter dan 45,8 meter. Lebar jembatan 12,7 meter yang ditopang oleh balok prategang sebanyak 6 buah dengan jarak spasi 2,1 meter dan disimulasikan ditopang oleh perletakan bantalan elastomer (elastomer bearing pads) tipe berlapis.

Tujuan Simulasi perancangan perletakan elastomer adalah untuk mengetahui spesifikasi perletakan elastomer pada SNI 3967:2013 dan memahami perhitungan perencanaan perletakan elastomer berdasarkan pedoman perancangan elastomer untuk perletakan jembatan yang diterbitkan oleh Kementrian PUPR pada tahun 2015. Menurut pedoman tersebut beban yang terima oleh bantalan yang harus dihitung adalah beban hidup ditambah beban mati rencana. Perhitungan harus mengkonversi beban-beban yang bekerja menjadi tegangan rata-rata pada luas bidang bantalan yang menerima beban seperti persamaan di bawah ini:

$$
\begin{gathered}
\sigma_{S}=\frac{P_{D L}+P_{L L}}{A} \\
\sigma_{L}=\frac{P_{L L}}{A}
\end{gathered}
$$

dimana $\sigma_{\mathrm{s}}$ sama dengan nilai tegangan rata-rata yang disebabkan oleh seluruh beban (MPa), $\sigma_{\mathrm{L}}$ sama dengan nilai tegangan rata-rata yang disebabkan oleh beban hidup ( $\mathrm{MPa}$ ), $\mathrm{P}_{\mathrm{DL}}$ sama dengan nilai beban mati rencana $(\mathrm{N}), \mathrm{P}_{\mathrm{LL}}$ sama dengan nilai beban hidup rencana $(\mathrm{N})$, dan A sama dengan nilai luas seluru permukaan $\left(\mathrm{mm}^{2}\right)$.

Besar faktor bentuk untuk lapisanlapisan elastomer tidak berlubang harus dihitung dengan persamaan sebagai berikut:

$$
\begin{aligned}
\mathbf{S} & =\frac{A}{\mathbf{I}_{\mathbf{p}} \times \mathbf{h}_{\mathrm{ri}}} \\
\mathbf{I}_{\mathbf{P}} & =2(\mathbf{L}+\mathbf{B}) \\
\mathbf{A} & =\mathbf{L} \times \mathbf{B}
\end{aligned}
$$

dimana S sama dengan nilai faktor bentuk, A sama dengan luas seluruh bidang permukaan $\left(\mathrm{mm}^{2}\right)$, Ip sama dengan nilai keliling elastomer, sudah masuk lubang (mm), $\mathrm{h}_{\mathrm{ri}}$ sama dengan nilai tebal efektif karet pada lapisan antara 
(mm), L sama dengan panjang efektif seluruh elastomer (mm), dan B sama dengan lebar efektif seluruh elastomer $(\mathrm{mm})$.

\section{METODE PENELITIAN}

Data primer jembatan diperoleh dari pengamatan langsug terhadap shop drawing dari denah dan potongan memanjang A-A underpass Sungai (Sei) Tanjung pada proyek pembangunan jalan tol Indrapura-Kisaran Segmen 5 dan data primer dimensi perletakan bantalan elastomer diperoleh dari SNI 3967:2013.

Alur perancangan perletakan elastomer dapat dilihat pada Gambar 1.

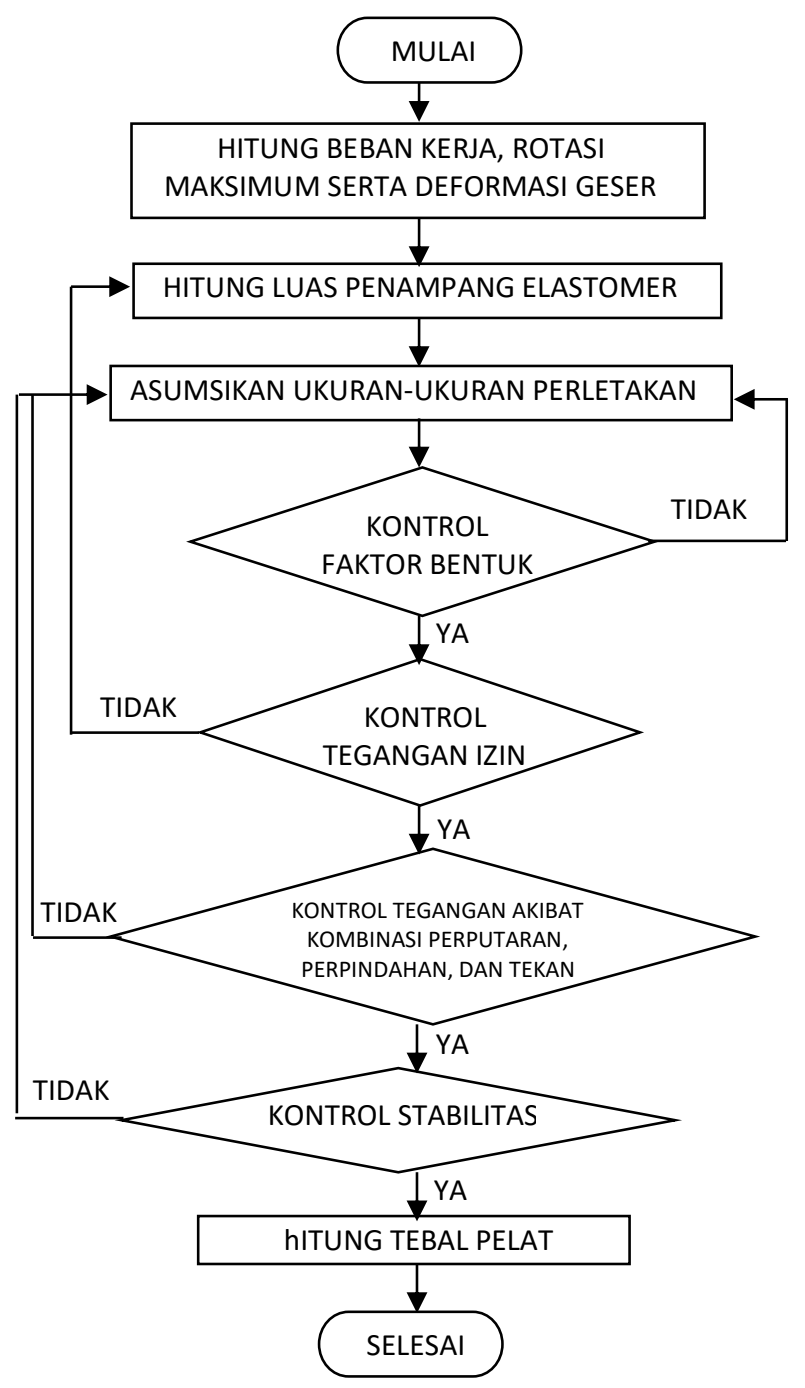

Gambar 1. Bagan alir proses perancangan perletakan elastomer

Sumber: Pedoman Perancangan Bantalan Elastomer untuk Perletakan Jembatan Tahun 2015

\section{HASIL DAN PEMBAHASAN}

\section{Hasil}

Data perencanaan jembatan Sungai Sei Tanjung pada proyek pembangunan jalan tol Indrapura-Kisaran Segmen 5, sebagai berikut:

- Bentang jembatan (L) $=45,8 \mathrm{~m}$

- Lebar lantai beton (B) $=12,7 \mathrm{~m}$

- Tebal pelat beton $\left(t_{s}\right)=0,25 \mathrm{~m}$

- Tebal aspal $\left(\mathrm{t}_{\mathrm{a}}\right)=0,05 \mathrm{~m}$

- Jarak antar gelagar (s) =0,05 m

- Modulus elastisitas beton Ec = 25332,084 MPa

- Luas penampang balok prategang $(\mathrm{A})=$ $0,752250 \mathrm{~m}^{2}$

- Momen inersia balok prategangkomposit (I) $=0,76060 \mathrm{~m}^{4}$

- Luas penampang balok diafragma $(\mathrm{A})=$ $0,355 \mathrm{~m}^{2}$

\section{Pembahasan}

Tabel 1. Rekapitulasi beban mati

\begin{tabular}{|c|c|r|}
\hline Beban mati & Beban Merata $(\mathrm{N} / \mathrm{m})$ & Gaya $(\mathrm{N})$ \\
\hline Pelat lantai & 13125 & 300563 \\
\hline Aspal + overlay & 2352 & 53861 \\
\hline Air hujan & 1029 & 23564 \\
\hline Barrier & 20923 & 479130 \\
\hline Gelagar & 18800 & 430250 \\
\hline Diafragma & 2622 & 59000 \\
\hline Total = & 58851 & 1346367 \\
\hline
\end{tabular}

Sumber: Hasil perhitungan 
Tabel 2. Rekapitulasi beban hidup

\begin{tabular}{|c|c|r|}
\hline Beban Hidup & Beban Merata $(\mathrm{N} / \mathrm{m})$ & Gaya $(\mathrm{N})$ \\
\hline Beban BTR & 15645 & 358271 \\
\hline Beban BGT & & 51450 \\
\hline Total $\left(\mathrm{P}_{\mathrm{LL}}\right)=$ & 15645 & 409721 \\
\hline
\end{tabular}

Sumber: Hasil perhitungan

\section{a. Deformasi Geser}

Deformasi akibat rangkak

$\Delta_{\text {cr }}=\frac{\mathrm{t}^{0,6}}{10 \times \mathrm{t}^{0,6}} \times \mathrm{C}_{u} \times \epsilon_{\mathrm{e}} \times \mathrm{L}$

Dimana $t$ sama dengan nilai umur rencana pembebanan (1000 tahun = 365000 hari), Cu sama dengan nilai koefisian rangkak max, nilai $\mathrm{Cu}=2,5$ untuk $\mathrm{fc}^{\prime}=29,05 \mathrm{MPa}$, dan $\epsilon_{\mathrm{e}}$ sama dengan nilai regangan elastis sesaat akibat tegangan tetap

$$
\epsilon_{e}=\frac{0,7 \times \sqrt{\mathrm{fc} \prime}}{\mathrm{Ec}}=0,000149=1,49 \cdot 10^{-4}
$$

$\Delta_{\mathrm{cr}}=\frac{365000^{0,6}}{10+365000^{0,6}} 2,5 \cdot 1,49.10^{-4} \cdot 45800$

$\Delta \mathrm{cr}=17,06 \mathrm{~mm}$

\section{Deformasi akibat susut (shrinkage)}

$\Delta_{\mathrm{sh}}=\frac{\mathrm{t}}{35+\mathrm{t}} \times \epsilon_{\mathrm{csu}} \times \mathrm{L}$

Dimana $\mathrm{t}$ sama dengan nilai usia beton yang jaga kelembabannya di lokasi pekerjaan, terhitung sejak 7 hari - 20 hari, $\epsilon_{\text {csu }}$ sama dengan nilai koefisien susut max, nilai $\in_{\mathrm{csu}}=0,00017$ untuk fc' $=29,05$ MPa.

$$
\begin{aligned}
& \Delta_{\text {sh }}=\frac{20}{35+20} \times 0,00017 \times 45800 \\
& \Delta_{\text {sh }}=2,83 \mathrm{~mm}
\end{aligned}
$$

Deformasi akibat perbedaan suhu

$$
\begin{gathered}
\Delta \mathrm{L}=\mathrm{L} \times \alpha \times \Delta \mathrm{T} \\
\Delta \mathrm{L}=45800 \cdot 10 \cdot 10^{-6} \cdot 1 / 2(40-15) \\
\Delta \mathrm{L}=5,73 \mathrm{~mm}
\end{gathered}
$$

Total deformasi

$$
\begin{aligned}
& \Delta_{\text {total }}=\frac{1}{2} \times\left(\Delta_{\text {cr }}+\Delta_{\text {sh }}+\Delta \mathrm{L}\right) \\
& \Delta_{\text {total }}=\frac{1}{2} \times(17,06+2,83+5,73) \\
& \Delta_{\text {total }}=12,81 \mathrm{~mm}
\end{aligned}
$$

Maka deformasi geser rencana:

$\Delta_{\mathrm{s}}=12,81 \mathrm{~mm}$

Deformasi ijin:

$\Delta_{\mathrm{ijin}}=2 \cdot \Delta_{\mathrm{s}}=2 \cdot 12,81=25,62 \mathrm{~mm}$

- Kontrol Deformasi Geser

Tebal total lapisan karet elastomer:

$\mathrm{h}_{\mathrm{rt}}=2 \mathrm{hr}_{\text {cover }}+\left(\mathrm{N}_{\text {layer }}-1\right) \mathrm{hr}_{\text {internal }}$

$\mathrm{h}_{\mathrm{rt}}=2 \cdot 11,5+(7-1) 16,5=122 \mathrm{~mm}$

Syarat: $h_{r t} \geq \Delta_{\mathrm{ijin}}$

Dari hitungan sebelumnya $\mathrm{hr}_{\mathrm{t}}=122 \mathrm{~mm}$ dan $\Delta_{\mathrm{ijin}}=25,62 \mathrm{~mm}$, berarti tebal total elastomer memenuhi syarat

- Rotasi maksimum

Rotasi (perputaran sudut) balok girder pada bagian ujung (bagian yang diberi perletakan) akibat beban terbagi rata, sebagai berikut:

$$
\begin{aligned}
& \theta=\frac{\left(q_{D L}+q_{L L}\right) L^{3}}{24 E I} \\
& \theta_{1}=\frac{\left.(58851+15645) 22,9^{3}\right)}{24.2,5332084 \cdot 10^{10} \cdot 0,76060} \\
& \theta_{1}=0,00193 \mathrm{rad}
\end{aligned}
$$


Rotasi balok girder pada bagian ujung akibat beban terpusat, sebagai berikut:

$\theta_{2}=\frac{P L^{2}}{32 E I}$

$\theta_{2}=\frac{51450 \cdot 22,9^{2}}{32 \cdot 2,5332084 \cdot 10^{10} \cdot 0,76060}$

$\theta_{2}=0,00035 \mathrm{rad}$

Rotasi balok girder pada bagian ujung, sebagai berikut:

$\theta_{\mathrm{t}}=\theta_{1}+\theta_{2}=0,00193+0,00035=0,00228 \mathrm{rad}$

b. Luas area elastomer yang diperlukan

$\mathrm{A}_{\text {perlu }}>\mathrm{P}_{\text {total }} /$ batas tegangan delaminasi

$A_{\text {perlu }}>\left(P_{D L}+P_{L L}\right) / \sigma$

Aperlu $>(1346367+409721) / 7$

Aperlu $>250869,7 \mathrm{~mm}^{2}$

Perletakan yang direncanakan memakai elastomer laminasi, dengan memakai karet sintesis (Neoprene) yang memiliki modulus geser minimum sebesar 0,60 MPa dan kuat tarik minimum sebesar 15,5 Mpa.

Data primer perletakan bantalan elastomer, sebagai berikut:

- Mutu baja pelat (fy) $=260 \mathrm{MPa}$

- Jumlah lapisan baja $\left(\mathrm{N}_{\text {layer }}\right)=7$ lapis

- Panjang elastomer (L) $=65 \mathrm{~cm}$

- Lebar elastomer $(\mathrm{W})=60 \mathrm{~cm}$

- Luas area elastomer $(\mathrm{A})=3900 \mathrm{~cm}^{2}$

- Tebal lapisan elastomer $\left(\mathrm{h}_{\mathrm{rt}}\right)=12,2 \mathrm{~cm}$

- Tebal cover $\left(\mathrm{hr}_{\text {cover }}\right)=1,15 \mathrm{~cm}$

- Tebal lapisan dalam ( $\left.\mathrm{hr}_{\text {internal }}\right)=1,65 \mathrm{~cm}$

- Kekerasan nominal = 55 skala shore "A"

- Batas fatik $\left(\mathrm{F}_{\mathrm{TH}}\right)=31 \mathrm{MPa}$
- Batas tegangan delaminasi $(\sigma)=7 \mathrm{MPa}$

Syarat yang harus dipenuhi dalam menentukan tebal lapisan elastomer, yaitu:

1. Seluruh tebal lapisan elastomer bagian dalam harus mempunyai nilai tebal yang sama.

2. Tebal lapisan penutup tidak boleh lebih dari 70\% tebal lapisan internal.

c. Faktor bentuk

Faktor bentuk (S) harus berada dalam Batasan berikut ini:

1. Untuk bantalan polos $1<\mathrm{S} \leq 4$

2. Untuk bantalan berlapis $4<\mathrm{S} \leq 12$.

Tebal lapisan dalam elastomer:

$\mathrm{hr}_{\text {internal }}=16,5 \mathrm{~mm}$, maka:

syarat: $\mathrm{hr}_{\text {cover }} \leq 0,7 \mathrm{hr}_{\text {internal }}$

$$
11,5 \mathrm{~mm} \leq 0,7(16,5 \mathrm{~mm})
$$

$11,5 \mathrm{~mm} \leq 11,55 \mathrm{~mm}$ (sesuai syarat)

$\mathrm{S}_{\text {cover }}=\frac{\mathrm{A}}{2 \times(\mathrm{L}+\mathrm{W}) \times \mathrm{hr}_{\text {cover }}}$

$S_{\text {cover }}=\frac{390000}{2 \times(650+600) \times 7,5}=13,565$

$\mathrm{S}_{\text {internal }}=\frac{\mathrm{A}}{2 \times(\mathrm{L}+\mathrm{W}) \times \mathrm{hr}_{\text {internal }}}$

$S_{\text {internal }}=\frac{390000}{2 \times(650+600) \times 16,5}=9,455$

d. Tegangan Tekan

$\sigma_{\mathrm{s}}=\frac{\mathrm{P}_{\text {total }}}{\mathrm{A}}=\frac{1756087,9}{390000}=4,502 \mathrm{MPa}$

- Kontrol Tegangan Tekan

Tegangan tekan yang terjadi pada elastomer harus memenuhi syarat: 
$\sigma_{\mathrm{s}} \leq \mathrm{G}$. S Sinternal $=0,60 \cdot 9,455=5,200 \mathrm{MPa}$

Dari hitungan sebelumnya $\sigma_{\mathrm{s}}=4,502 \mathrm{MPa}$ berarti tegangan tekan yang terjadi masih memenuhi syarat.

- Kontrol Rotasi

Syarat:

$$
\sigma_{\mathrm{s}} \geq \frac{1}{2} \times \mathrm{G} \times \mathrm{S}_{\text {internal }} \times\left(\frac{\mathrm{L}}{\mathrm{hr}_{\text {int }}}\right)^{2} \times \frac{\theta}{\mathrm{N}_{\text {layer }}}
$$

$\sigma_{\mathrm{s}} \geq \frac{1}{2} \times 0,60 \times 12,739 \times\left(\frac{500}{11}\right)^{2} \times \frac{0,00228}{7}$

$\sigma_{\mathrm{s}} \geq 1,434 \mathrm{MPa}$

Dari perhitungan sebelumnya $\sigma_{\mathrm{s}}=4,502$ $\mathrm{MPa}$, berarti perletakan elastomer yang dipakai memenuhi syarat rotasi

e. Defleksi Tekan

$\varepsilon_{\text {int }}=\frac{\sigma_{\mathrm{s}}}{6 \times \mathrm{G} \times \mathrm{S}_{\text {internal }}{ }^{2}}$

$\varepsilon_{\text {int }}=\frac{4,502}{6 \times 0,60 \times 9,455^{2}}=0,012$

Maka defleksi akibat kejut adalah:

$\delta_{\text {int }}=2 G_{\text {int. }} \mathrm{hr}_{\text {cover }}+\left(N_{\text {layer }}-1\right) G_{\text {int. }} \mathrm{hr}_{\text {inter }}$

$\delta_{\text {int }}=2 \cdot 0,012 \cdot 11,5+(7-1) 0,012 \cdot 16,5$

$\delta_{\text {int }}=1,464 \mathrm{~mm}$

Defleksi akibat susut:

$$
\begin{aligned}
\delta_{\text {susut }} & =\text { Cd. } \delta_{\text {int }} \\
& =0,25 \cdot 1,464 \\
& =0,366 \mathrm{~mm}
\end{aligned}
$$

Defleksi total

$$
\begin{aligned}
\delta_{\text {Total }} & =\delta_{\text {susut }}+\delta_{\text {int }} \\
& =(0,366+1,464) \mathrm{mm} \\
& =1,830 \mathrm{~mm}
\end{aligned}
$$

- Kontrol Defleksi Tekan
Kontrol defleksi tiap lapisan elastomer tidak boleh melebihi 0,07 $\mathrm{hr}_{\text {int, }}$ maka:

$\delta_{\text {Lapisan }}=\mathrm{G}_{\text {int }} \cdot \mathrm{hr}_{\text {internal }}$

$\delta_{\text {Lapisan }}=0,012 \cdot 16,5=0,198 \mathrm{~mm}$

syarat: $\delta_{\text {Lapisan }}<0,07 . \mathrm{hr}_{\text {int }}$

$$
\delta_{\text {Lapisan }}<0,07.11=0,77 \mathrm{~mm}
$$

Defleksi setiap lapisan memenuhi syarat

f. Tebal Pelat Baja

Kondisi layan,

Syarat: hs $\geq 3 \times \mathrm{hr}_{\text {internal }} \times \sigma \mathrm{s} / \mathrm{fy}$

hs $\geq 3 \times 16,5 \times 4,503 / 260$

hs $\geq 0,929 \mathrm{~mm}$

Kondisi fatik,

$\sigma_{\mathrm{L}}=\frac{\mathrm{PLL}}{\mathrm{A}}=\frac{409720,5}{300000}=1,37 \mathrm{MPa}$

Syarat: $\mathrm{h}_{\mathrm{st}} \geq 2 \times \mathrm{hr}_{\text {internal }} \times \sigma_{L} / F_{T H}$

$h_{\text {st }} \geq 2 \times 16,5 \times 1,37 / 31$

$\mathrm{h}_{\mathrm{st}} \geq 1,1183 \mathrm{~mm}$

Maka direncanakan tebal pelat baja, $\mathrm{h}_{\mathrm{st}}=$ $2 \mathrm{~mm}$.

g. Kontrol stabilitas

Tebal keseluruhan elastomer:

$\mathrm{H}=2 \mathrm{hr}_{\text {cover }}+\left(\mathrm{N}_{\text {layer }}-1\right) \mathrm{hr}_{\text {internal }}+\mathrm{N}_{\text {layer }}$ $\mathrm{h}_{\mathrm{st}}$

$H=2 \times 11,5+(7-1) \times 16,5+7 \times 2$

$\mathrm{H}=136 \mathrm{~mm}$

Syarat pertama: $\mathrm{H} \leq \mathrm{L} / 3$

$\mathrm{H} \leq 650 / 3=216,67 \mathrm{~mm}$

Syarat kedua: $\mathrm{H} \leq \mathrm{W} / 3$

$$
\mathrm{H} \leq 600 / 3=200 \mathrm{~mm}
$$


Dari perhitungan sebelumnya $\mathrm{H}=136$

$\mathrm{mm}$, berarti elastomer yang dipakai memenuhi syarat stabilitas.

\section{SIMPULAN}

Hasil perhitungan kontrol pada pembahasan menunjukan perletakan elastomer yang dipakai memenuhi persyarat: tebal lapisan, tegangan tekan, rotasi, defleksi tekan, deformasi geser dan stabilitas.

\section{DAFTAR PUSTAKA}

Siregar, H.H. (2021). Perencanaan Struktur Jembatan Sungai Sei Tanjung Segmen 5 Sta 113+904 Pada Proyek Pembangunan Jalan Tol Trans Sumatera Bagian Pekerjaan Jalan Tol Ruas Indrapura - Kisaran. Laporan Tugas Akhir. Medan. Politeknik Negeri Medan.

Ansori, M.Y. Gardjito E. \& Winarto S. (2021). Perencanaan Ulang Struktur Jembatan Golo Desa Tumpakoyot Blitar dengan Sistem Girder Pelat Baja. Jurmateks. 4(1):89-103.

Sugiyono R.D (2016). Analisa Perencanaan Struktur Atas Jembatan Rangka Baja Tipe Camel Back Truss. Rekats. 3(3):88-93.

Setyorini, I. \& Astuti, E.S. (2016). Kajian Spesifikasi Teknis Dan Metode Uji Bantalan Karet (Elastomer) Untuk Perletakan Jembatan. Prosiding Seminar Nasional Kulit, Karet dan Plastik Ke-5, Yogyakarta, 26 Oktober 2016

Kementrian Pekerjaan Umum dan Perumahan Rakyat RI, 2015. Pedoman Perancangan Bantalan Elastomer untuk Perletakan Jembatan Tahun 2015.

Badan Standardisasi Nasional. 2013. Spesifikasi dan metode uji bantalan karet (elastomer) untuk perletakan jembatan (SNI 3967:2013)

Badan Standardisasi Nasional. 2004. Perencanaan struktur beton untuk jembatan (RSNI T-122004) 